\title{
Gas-Phase Interactions Between Lead(II) Ions and Thiouracil Nucleobases: A Combined Experimental and Theoretical Study
}

\author{
Jean-Yves Salpin, ${ }^{\text {a }}$ Sébastien Guillaumont, ${ }^{\text {a }}$ Jeanine Tortajada, ${ }^{\text {a }}$ and \\ Al Mokhtar Lamsabhi ${ }^{\mathrm{b},+}$ \\ a Université d'Evry Val d'Essonne, Laboratoire d'Analyse et Modélisation pour la Biologie et \\ l'Environnement (LAMBE), Evry, France

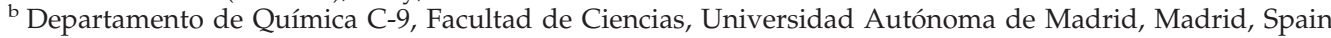

\begin{abstract}
The gas-phase interactions between lead(II) ions and 2-thiouracil, 4-thiouracil, and 2,4dithiouracil have been investigated by combining mass spectrometry and theoretical calculations. The most abundant complexes observed, namely $\left[\mathrm{Pb}(\text { thiouracil) }-\mathrm{H}]^{+}\right.$, have been studied by MS/MS experiments. Cationization by the metal allows an unambiguous characterization of the sulfur position, several fragment ions being specific of each isomer. Moreover, compared with the uracil fragmentation, new fragmentation channels are observed: elimination of $\mathrm{PbS}$ or total reduction of the metal. Calculations performed on the different structures, including tautomers, show that sulfur is the preferred complexation site, suggesting the greater affinity of lead for sulfur. The most stable structures are always preferentially bidentate. Natural population analysis indicates a charge transfer from the base to the metal with a more pronounced covalent character for sulfur compared to oxygen. Energetic profiles associated with the main fragmentations have been described. (J Am Soc Mass Spectrom 2009, 20, 359-369) () 2009 Published by Elsevier Inc. on behalf of American Society for Mass Spectrometry
\end{abstract}

$\mathrm{I}$ nvestigations about the way metal cations interact with biological molecules are essential for a better assessment of the role and effects of metal ions in biological systems. These studies are carried out not only in solution but also in the gas phase because information on the intrinsic reactivity is often crucial to understand the behavior of many biological systems that cannot be simply rationalized in terms of reactivity in solution.

Lead is now well established as a highly toxic metal. Different works have demonstrated that its toxicity is partly due to its interactions with nucleic acids, lead(II) ions being particularly efficient in RNA depolymerization [1-4]. Despite these known effects, the gas-phase chemistry between lead(II) ions and small nucleic acid building blocks had not been explored yet. In this context, we recently addressed a detailed study on the gas-phase interactions of lead(II) ions with uracil and thymine $[5,6]$. In the present report, we have extended our investigations to thiouracil derivatives. These compounds are of particular interest not only because they

Address reprint requests either to Dr. J.-Y. Salpin, Université d'Evry Val d'Essonne, Laboratoire Analyse et Modélisation pour la Biologie et l'Environnement (LAMBE), CNRS, UMR 8587, Bâtiment Maupertuis, Boulevard François Mitterrand, 91025 Evry, France. E-mail: Jean-Yves.Salpin@ univ-evry.fr, or to Dr. A. M. Lamsabhi, Universidad Autónoma de Madrid, Departemento de Química C-9, Facultad de Ciencias, Cantoblanco, E-28049 Madrid, Spain.. E-mail: mokhtar.lamsabhi@uam.es are minor components of $t$-RNA [7], but also due to their mutagenic, anticancer, and antithyroid activities [8]. Consequently, a detailed knowledge of structural and reactivity changes induced by substitution of one or both oxygen atoms by the more polarizable sulfur atom is helpful to understand the underlying reasons of their different role in biological activity. Recently, the gas-phase protonation of thiouracil derivatives [9] and their association with $\mathrm{Cu}^{+}$[10], $\mathrm{Cu}^{2+}$ [11-13], $\mathrm{Ca}^{2+}$ [14], and alkali metals [15] were examined. In the present study, electrospray ionization was used to generate $\mathrm{Pb}^{2+}$ /thiouracil complexes. The advent of electrospray ionization indeed enabled the easy formation of gaseous complexes involving metal dications [16], and therefore to gain direct information about the intrinsic reactivity of organic and biological molecules when interacting with metal dications. However, to obtain a detailed picture of the reactivity patterns, one needs to propose appropriate reaction mechanisms accounting for the experimental observations. This was presently achieved by combining mass spectrometry experiments with theoretical calculations in the framework of density functional theory (DFT).

\section{Experimental}

Electrospray mass spectra were recorded on an Applied Biosystems/MDS SCIEX API2000 triple-quadrupole in- 
strument fitted with a "turboionspray" ion source. Solutions of lead nitrate/nucleobase at various concentrations were prepared in a water/methanol mixture $(50 / 50 \mathrm{vol} / \mathrm{vol})$, and were introduced in the source using direct infusion with a syringe pump, at a flow rate of $5 \mu \mathrm{L} / \mathrm{min}$. Ionization of the samples was achieved by applying a voltage of $5.5 \mathrm{kV}$ on the sprayer probe and by the use of a nebulizing gas (GAS1, air) surrounding the sprayer probe, intersected by a heated gas (GAS2, air) at an angle of $90^{\circ}$. The operating pressure of GAS1 and GAS2 are adjusted to 2.1 bars by means of an electronic board (pressure sensors), as a fraction of the air inlet pressure. The curtain gas $\left(\mathrm{N}_{2}\right)$, which prevents air or solvent from entering the analyzer region, was similarly adjusted to a value of 1.4 bars. The temperature of GAS2 was set at $100{ }^{\circ} \mathrm{C}$.

MS/MS spectra were carried out by introducing nitrogen as collision gas in the second quadrupole. Setting the CAD parameter to 6 during MS/MS experiments resulted in pressure values of roughly $3 \times 10^{-5}$ Torr as measured by the ion gauge located outside the collision cell. It has been reported [17] that the pressure inside a linac collision cell is actually in the order of 10 mTorr. Given the length of the second quadrupole and the pressure of nitrogen, we are in a multiple collision regime that will further increase the internal energy content of the precursor ion. As detailed later, the declustering potential (DP), defined as the difference of potentials between the orifice plate and the skimmer (grounded), and typically referred to as the "cone voltage" for other electrospray interfaces, was fixed to $60 \mathrm{~V}$ to perform most of the MS/MS experiments. Furthermore, MS/MS spectra were recorded at different collision energies (the kinetic energy of ions is given by the difference of potentials between the focusing quadrupole Q0 preceding Q1, and the collision cell Q2).

Unless otherwise noted, mass to charge ratios mentioned throughout this paper correspond to the peaks including the most abundant lead isotope $\left({ }^{208} \mathrm{~Pb}\right)$. Nucleobases and lead nitrate were purchased from Aldrich and were used without further purification.

\section{Computational}

DFT calculations were carried out using B3LYP and G96LYP density functionals, as implemented in the Gaussian-03 set of programs [18]. B3LYP and G96LYP combines the nonlocal correlation function of Lee et al. [19], with the Becke's three-parameter nonlocal hybrid exchange functional [20], and the 1996 exchange functional of Gill [21], respectively.

In a first step, the different structures were optimized with the dp-polarized 6-31G $(\mathrm{d}, \mathrm{p})$ basis, without any symmetry constraint. All the structures studied were designed to be initially planar ( $\sigma$-complexes), except for those corresponding to some attempts to locate $\pi$-complexes. Harmonic vibrational frequencies were estimated at this level to classify the stationary points as local minima or saddle points, and to estimate the zero-point vibrational energy (ZPE) corrections. Finally, relative energies were determined using the 6-311+ $\mathrm{G}(3 \mathrm{df}, 2 \mathrm{p})$ extended basis set.

Different effective core potentials have been proposed in the literature for $\mathrm{Pb}$. In the present study, we used the "Stuttgart" quasi-relativistic pseudo-potential developed by Küchle et al. [22] This particular 78 core-electrons ECP employs a $(4 \mathrm{~s}, 4 \mathrm{p}, 1 \mathrm{~d}) /[2 \mathrm{~s}, 2 \mathrm{p}, 1 \mathrm{~d}]$ basis set with a $(3,1)$ contraction scheme for $s$ and $p$ functions that can be used directly in conjunction with the standard 6-31G(d,p) Pople basis set describing C, N, $\mathrm{O}$, and $\mathrm{H}$ atoms.

To perform single-point calculations at a higher level of theory, we recently developed for lead [23] 6-311+ $\mathrm{G}(2 \mathrm{df})$ and 6-311+G(3df) extended basis sets. We demonstrated that these basis sets, when combined with the G96LYP/Stuttgart approach, yield binding enthalpies in close agreement with those obtained at the QCISD(T)/Stuttgart and CCSD(T)/Stuttgart levels of theory, but with significantly shorter computational times. It also turned out that G96LYP/Stuttgart and B3LYP/Stuttgart approaches provide similar relative energies and constitute a good compromise between accuracy and computational cost for binding energy calculations. Finally, given the fact that B3LYP is well suited for both the description of ion-molecule complexes [24-26] and the study of inter- and intramolecular hydrogen bonds [27-29], we carried out both B3LYP and G96LYP calculations.

For the sake of simplicity, the basis sets used for $\mathrm{Pb}$ will be referred to as $6-31 G(d, p)$ and $6-311+G(3 d f, 2 p)$ basis sets throughout the text.

To give a picture of the charge distribution within the different species, we have carried out for all the structures investigated a natural population analysis (NPA) at the B3LYP/6-31G(d,p) level by means of the NBO program [30]. The bonding within the individual equilibrium structures was also analyzed by locating the bond critical points (BCP) using atoms-in-molecules (AIM) theory [31-32], which is based on a topological analysis of the electronic density at the BCPs, and is a good descriptor of the bond strength or weakness.

Throughout this paper, total energies are expressed in Hartree and relative energies in $\mathrm{kJ} \mathrm{mol}^{-1}$. Unless otherwise noted, the relative energies given hereafter are those obtained at a level equivalent to either B3LYP/ 6-311+G(3df,2p)//B3LYP/6-31G(d,p)+ZPE or G96LYP/6$311+\mathrm{G}(3 \mathrm{df}, 2 \mathrm{p}) / / \mathrm{G} 96 \mathrm{LYP} / 6-31 \mathrm{G}(\mathrm{d}, \mathrm{p})+$ ZPE. Detailed geometries of all the structures mentioned in this paper (neutral nucleobases, thiouracilates, and $\mathrm{Pb}^{2+}$-complexes) are available from authors upon request.

\section{Results and Discussion}

\section{Mass Spectrometry}

Positive ion electrospray spectrum of $\mathrm{Pb}\left(\mathrm{NO}_{3}\right)_{2}$ /thiouracil mixture. A typical positive-ion electrospray spectrum of a water/methanol mixture of lead nitrate and 2- 


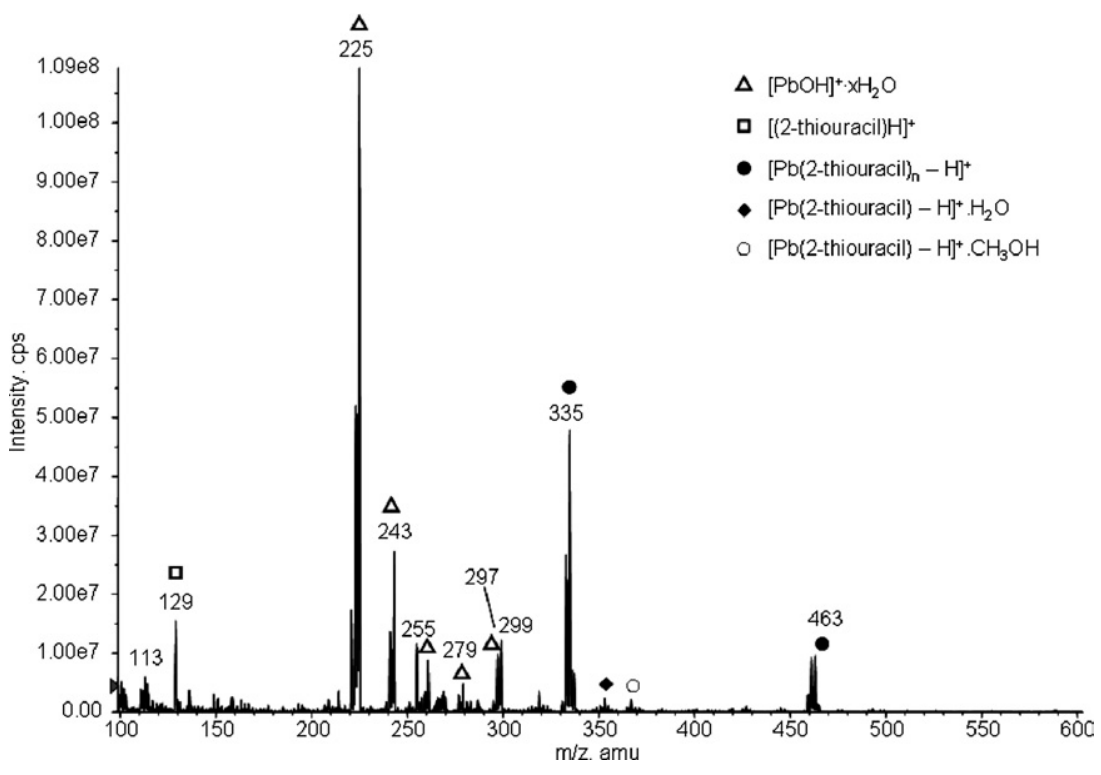

Figure 1. Positive-ion electrospray spectrum of a $5 \times 10^{-5} \mathrm{~mol} \mathrm{~L}^{-} / 10^{-4} \mathrm{~mol} \mathrm{~L}^{-} \mathrm{Pb}\left(\mathrm{NO}_{3}\right)_{2} /$ 2-thiouracil water/methanol solution (50/50).

thiouracil with a DP value set to $40 \mathrm{~V}$ is given in Figure 1. Lead-containing ions can be easily identified because of the specific isotopic distribution of this metal, resulting in characteristic triplets (if one omits the very weak ${ }^{204} \mathrm{~Pb}$ contribution). The declustering potential was varied from 0 to $200 \mathrm{~V}$.

In our previous study [5], we tried different concentrations for the $\mathrm{Pb}\left(\mathrm{NO}_{3}\right)_{2} /$ nucleobase mixture and noticed that intense lead/nucleobase complexes were observed at rather low concentrations. Consequently, we only worked with a $5 \times 10^{-5} \mathrm{~mol} \mathrm{~L}^{-1} / 10^{-4} \mathrm{~mol} \mathrm{~L}^{-1}$ ratio. We also opted for a water/methanol (50:50) solvent mixture which limits the extent of nucleobase protonation. Consistently, the intensity of protonated 2-thiouracil appears rather weak (Figure 1). With such conditions, we did not observe any doubly-charged ions, regardless of the solvent mixture composition. From Figure 1, we can see that the electrospray spectrum at $\mathrm{DP}=40 \mathrm{~V}$ is dominated by the lead hydroxide species $(m / z 225)$. This ion can be surrounded by several molecules of water (up to 5 molecules at the lowest DP value, $0 \mathrm{~V}$ ). These hydrated ions gradually disappear while adopting harsh interface conditions. At the highest DP $(200 \mathrm{~V})$, bare lead ion $\mathrm{Pb}^{+}(\mathrm{m} / \mathrm{z} 208)$ is the base peak. Note also that at $0 \mathrm{~V}$, the most abundant species are detected below $\mathrm{m} / \mathrm{z} 100$ (presently not shown) and correspond to protonated clusters of solvent (water and/or methanol).

The most abundant lead/thiouracil complexes observed are of general formula $\left[\mathrm{Pb}(\text { thiouracil })_{\mathrm{n}}-\mathrm{H}\right]^{+}$ $(n=1,2)$, and involve deprotonation of one nucleobase. Increasing the DP parameter induces in-source fragmentation of these complexes, but only to a minor extent. Monosolvated $[\mathrm{Pb}(\text { thiouracil })-\mathrm{H}]^{+}$ions are also detected in weak abundance at $\mathrm{m} / \mathrm{z} 353$ (water) and $\mathrm{m} / \mathrm{z} 367$ (methanol). Precursor ion scans suggest that the $m / z 335(n=1)$ ions would only arise from $m / z 463(n=$ 2) by loss of intact thiouracil. However, like for uracil and thymine, one may reasonably assume other processes to occur, such as proton transfer reactions between the nucleobase and ions like $\mathrm{PbOH}^{+}$or $\mathrm{PbNO}_{3}{ }^{+}$, present in solution. In addition, dissociative proton transfer from transiently formed $\left[\mathrm{Pb}(\text { thiouracil) })_{\mathrm{m}}\right]^{2+}$ complexes $(m \geq 2)$ cannot be ruled out given that such complexes have been observed for uracil and thymine [5].

In summary, $[\mathrm{Pb} \text { (thiouracil) }-\mathrm{H}]^{+}$ions are the most abundant species resulting from the interaction between $\mathrm{Pb}^{2+}$ and thiouracils, and the paper will now focus on their structural characterization, by means of MS/MS experiments and theoretical calculations. These ions will be labeled $[\mathrm{Pb}(2 \mathrm{SU})-\mathrm{H}]^{+},\left[\mathrm{Pb}(4 \mathrm{SU}-\mathrm{H}]^{+}\right.$, and $[\mathrm{Pb}(24 \mathrm{SU})-\mathrm{H}]^{+}$for 2-thiouracil, 4-thiouracil, and 2,4-dithiouracil, respectively.

Low-energy CID spectra of $[\mathrm{Pb} \text { (thiouracil) }-\mathrm{H}]^{+}$ions. MS/MS spectra of $[\mathrm{Pb}(2 \mathrm{SU})-\mathrm{H}]^{+},[\mathrm{Pb}(4 \mathrm{SU})-\mathrm{H}]^{+}$, and $[\mathrm{Pb}(24 \mathrm{SU})$ $-\mathrm{H}]^{+}$complexes were systematically recorded at different collision energies, ranging between 5 and $35 \mathrm{eV}$ (in the laboratory frame) (see Figure 2).

Examination of Figure 2 shows that 2-thiouracil and 4-thiouracil can be easily distinguished based on their interaction with $\mathrm{Pb}^{2+}$ ions. Each complex indeed exhibits a specific dissociation pattern. Mass to charge ratios of the various fragment ions are summarized in Table 1. The $[\mathrm{Pb}(2 \mathrm{SU})-\mathrm{H}]^{+}$ion loses HNCS $(\mathrm{m} / \mathrm{z} 276)$ while the $[\mathrm{Pb}(4 \mathrm{SU})-\mathrm{H}]^{+}$isomer expels HNCO $(\mathrm{m} / z$ 292). Similarly, $[\mathrm{Pb}(2 \mathrm{SU})-\mathrm{H}]^{+}$generates $[\mathrm{Pb}(\mathrm{NCS})]^{+}(\mathrm{m} / z 266)$, while $[\mathrm{Pb}(4 \mathrm{SU})-\mathrm{H}]^{+}$leads to $[\mathrm{Pb}(\mathrm{NCO})]^{+}(\mathrm{m} / z 250)$. These fragmentations involve the cleavage of the pyrimidic ring and the C (2) carbonyl (or thiocarbonyl) is always involved. The same behavior has been observed 

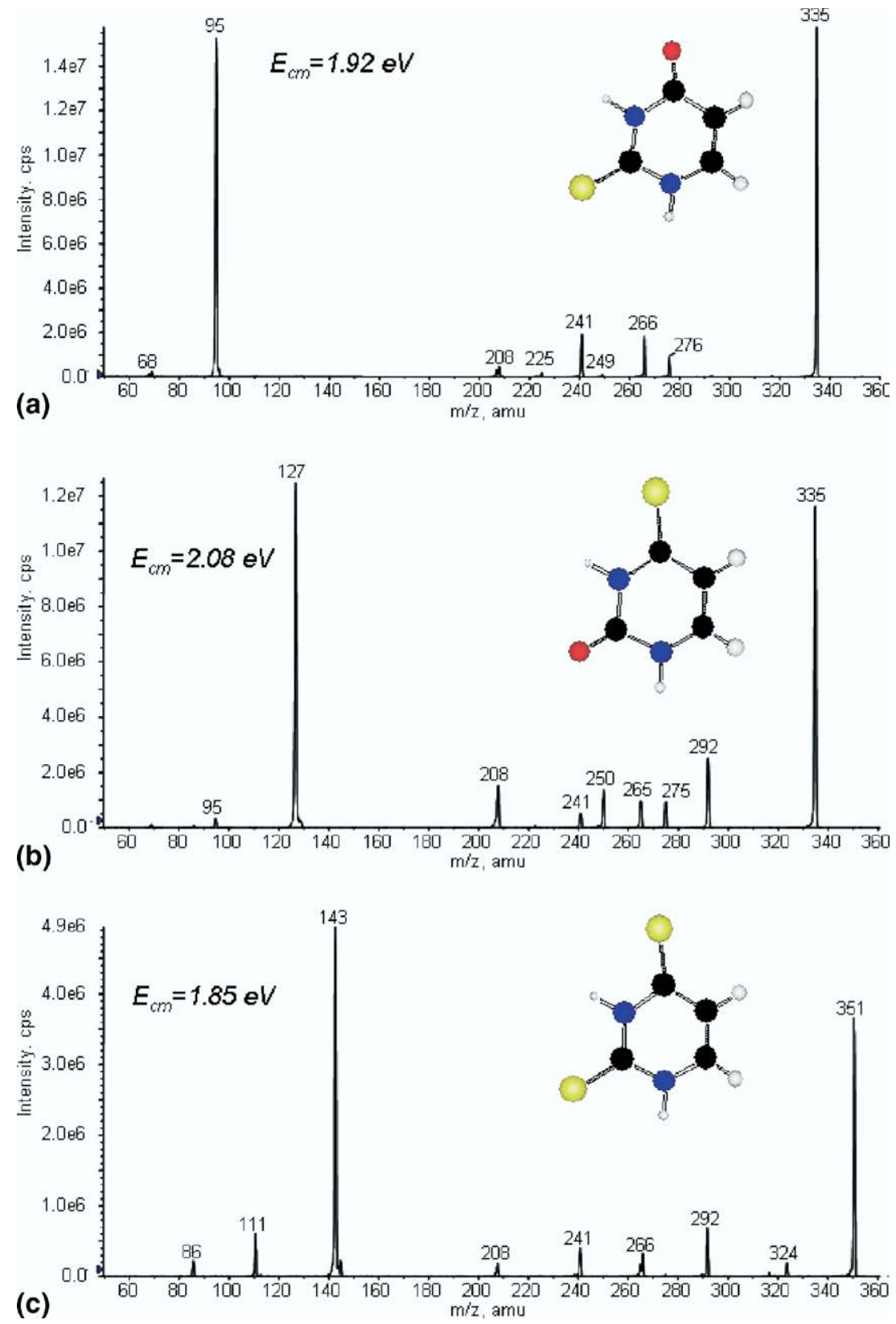

Figure 2. Typical low-energy CID spectra of (a) $[\mathrm{Pb}(2 \mathrm{SU})-\mathrm{H}]^{+}(m / z 335),(\mathbf{b})[\mathrm{Pb}(4 \mathrm{SU})-\mathrm{H}]^{+}(m / z$ $335)$, and $(\mathbf{c})[\mathrm{Pb}(24 \mathrm{SU})-\mathrm{H}]^{+}(\mathrm{m} / \mathrm{z} 351)$ ions obtained with nitrogen as collision gas. Collision energies are given in the center of mass frame.

for uracil and thymine, not only with $\mathrm{Pb}^{2+}[5]$, but also with $\mathrm{Cu}^{2+}$ [13] and $\mathrm{Ca}^{2+}$ ions [14]. These results also suggest a similar coordination mode of lead on uracil and thiouracils.

Two additional fragmentation channels observed with thiouracil derivatives result in particularly abundant ions: (1) $\mathrm{m} / \mathrm{z} 127$ (Figure $2 \mathrm{~b}$; elimination of the reduced metal $\mathrm{Pb}^{0}$ ) specifically observed with 4-thiouracil, and (2) elimination of a 240 neutral fragment observed with 2-thiouracil (Figure 2a), consistent with a PbS species and leading to the $\mathrm{m} / \mathrm{z} 95$ ion. These two dissociation channels are also observed with 2,4-dithiouracil $(\mathrm{m} / \mathrm{z}$ 143 and 111), the former (loss of $\mathrm{Pb}^{0}$ ) being clearly overwhelming. Globally, examination of Figure 2 shows that 4-thiouracil and 2,4-dithiouracil exhibit similar dissociative behavior. Note that such a complete metal reduction process was observed neither with copper nor with calcium. Interaction of alkali metal $\mathrm{M}^{+}$ towards uracil [33] and thiouracil [15] derivatives has been also explored, and bond dissociation energies for $\mathrm{Li}^{+}, \mathrm{Na}^{+}$and $\mathrm{K}^{+}$have been determined. The metal-ion $[\mathrm{M}(\mathrm{SU})]^{+}$complexes exhibit similar behavior upon CID, characterized by the loss of the intact neutral nucleobase. Alkali metals do not induce deprotonation of the nucleobases and are therefore monocoordinated, while the deprotonation observed with $\mathrm{Pb}^{2+}$ or $\mathrm{Cu}^{2+}$ ions 
Table 1. Summary of the main fragment ions observed on low-energy spectra of $[\mathrm{Pb} \text { (thiouracil) }-\mathrm{H}]^{+}$ions (base peak fragment is underlined)

\begin{tabular}{lccccc}
\hline & \multicolumn{5}{c}{ Product ions $(\mathrm{m} / \mathrm{z})$} \\
\cline { 2 - 6 } \multicolumn{1}{c}{ Precursor ion } & $-\mathrm{HCNO}$ & $-\mathrm{HNCS}$ & $-\mathrm{C}_{3} \mathrm{H}_{3} \mathrm{NO}$ & $-\mathrm{C}_{3} \mathrm{H}_{3} \mathrm{NS}$ & $-\mathrm{Pb}$ \\
\hline \hline$[\mathrm{Pb}(2 \mathrm{SU})-\mathrm{H}]^{+}(\mathrm{m} / \mathrm{z} 335)$ & - & 276 & 266 & - & $-\mathrm{PbS}$ \\
{$[\mathrm{Pb}(4 \mathrm{SU})-\mathrm{H}]^{+}(\mathrm{m} / \mathrm{z} 335)$} & 292 & - & - & 250 & $\underline{127}$ \\
{$[\mathrm{~Pb}(24 \mathrm{SU})-\mathrm{H}]^{+}(\mathrm{m} / \mathrm{z} 351)$} & - & 292 & - & 266 & $\underline{143}$ \\
{$[\mathrm{~Pb}(\mathrm{U})-\mathrm{H}]^{+}(m / z 319)^{\mathrm{a}}$} & 276 & - & 250 & - & - \\
\hline
\end{tabular}

${ }^{\text {a }}$ Reference [5].

results in a bidentate interaction inducing a greater structural perturbation of the pyrimidic ring, and subsequently a different behavior upon collision. In addition, the interaction between alkali metals and thiouracils is mostly electrostatic and alkali metals show a stronger affinity for oxygen than for sulfur. As we shall see later (vide infra), the interaction properties of lead(II) ions are also different for these two particular points.

Increasing the declustering potential induces insource fragmentation and therefore allows $\mathrm{MS}^{3}$-like experiments. We recorded MS/MS spectra of the main fragment ions; $m / z 95$ ions are characterized by intense elimination of 27 and $28 \mathrm{Da}$ that might correspond to $\mathrm{HCN}$ and $\mathrm{CO}$, respectively. Elimination of $\mathrm{HCN}$ is also detected on MS/MS spectra of $m / z 276$ and 292 species, leading to $m / z 249$ and 265, respectively. As for the $m / z$ 127 ion, the MS/MS spectrum appears not conclusive, the precursor ion certainly corresponding to a mixture of several species.

To rationalize these experimental findings, we have carried out theoretical calculations that enable us to discuss some aspects of the topology of the $[\mathrm{Pb}$ (thiouracil) $-\mathrm{H})]^{+}$PESs, as well as the structures and bonding characteristics of the most stable complexes.

\section{Computational Study}

Oxygen versus sulfur affinity. Elimination of $\mathrm{PbO}$ is not observed with uracil, while loss of $\mathrm{PbS}$ is significant for both 2-thiouracil and 2,4-dithiouracil. This finding sug-

Table 2. Calculated bond dissociation energies of $\mathrm{Pb}^{2+} /$ uracil and $\mathrm{Pb}^{2+}$ /thiouracil complexes

\begin{tabular}{lcc}
\hline Complex & $\mathrm{D}_{0}\left(\mathrm{~kJ} \mathrm{~mol}^{-1}\right)$ & Proton affinity $\left(\mathrm{kJ} \mathrm{mol}^{-1}\right)$ \\
\hline \hline U-X & 407.9 & \\
$\mathrm{U}-\mathrm{Y}$ & 453.9 & $874.5^{\mathrm{b}}$ \\
$2 \mathrm{SU}-\mathrm{X}$ & 435.6 & \\
$2 \mathrm{SU}-\mathrm{Y}$ & 458.1 & $879.9^{\mathrm{c}}$ \\
$4 \mathrm{SU}-\mathrm{X}$ & 414.2 & \\
$4 \mathrm{SU}-\mathrm{Y}$ & 473.2 & $883.2^{\mathrm{c}}$ \\
$24 \mathrm{SU}-\mathrm{X}$ & 442.9 & \\
$24 \mathrm{SU}-\mathrm{Y}$ & 479.4 & $887.0^{\mathrm{c}}$
\end{tabular}

a" $U$ " and "SU" stands for uracil and thiouracil, respectively. $X$ and $Y$ correspond to the heteroatom bonded to $C(2)$ and $C(4)$, respectively. ${ }^{b}$ Experimental value taken from reference [40]

'Experimental values taken from reference [9]. gests a greater affinity of $\mathrm{Pb}^{2+}$ towards sulfur than oxygen. To confirm or discard this statement, we compared the difference in affinity between sulfur and oxygen by estimating binding energies of $\mathrm{Pb}^{2+}$ ions on neutral molecules at a B3LYP/6-311+G(3df,2p)// B3LYP/6-31G(d,p) level. To this purpose, we only took into account the canonical forms, which are the most stable ones $[9,34-38]$ and the only structures likely to be present in the gas phase $[9,39]$. We have considered monodentate coordination either on $\mathrm{X}$ or $\mathrm{Y}$ heteroatom (C(2) or C(4) carbonyl or thiocarbonyl, respectively) (see Figure $1 S$ of the supplemental information, which can be found in the electronic version of this article). Dissociation energies $D_{0}$, calculated at $0 \mathrm{~K}$ are gathered in the Table 2 together with experimental proton affinities $[9,40]$. Note that the $D_{0}$ values were estimated without considering BSSEs, which are negligible at this level of theory [23]. Note also that experimental $D_{0}$ values are not available so far. Examination of Table 2 shows that the lead cation affinity follows the same trend as proton affinity. The strongest base is indeed 2,4-dithiouracil, followed by 4 -thiouracil, and finally 2-thiouracil. The preferred coordination site depends on two distinct effects. The first one is the nature and the position of the heteroatom involved. Comparison of the values obtained for U-X/2SU-X and U-Y/4SU-Y pairs shows that $\mathrm{Pb}^{2+}$ affinity is greater for sulfur than for oxygen, probably due to the greater polarizability of the former. The second effect is called "zwitterionic effect", as introduced by Lamsabhi et al. [9] during their study about the proton affinity of thiouracils. In fact, the analysis of the charge distribution of uracil and thiouracils showed that the contribution of zwitterionic resonance structures such Ib (Scheme 1) is important in this kind of interaction. The main consequence is traduced by the increased negative charge on the heteroatom at position $4(\mathrm{Y})$ in regards to the one attached to position

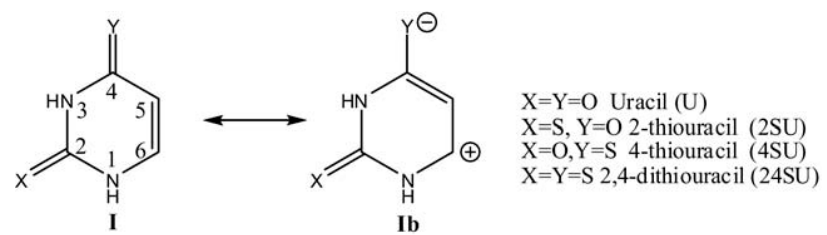

Scheme 1 
$2(X)$ and therefore the augmentation of its intrinsic basicity towards the incoming Lewis acid.

The zwitterionic effect is clearly illustrated by the data obtained for uracil and 2,4-dithiouracil, the Y site being the most basic one for these two molecules. This effect still dominates in the case of 2-thiouracil, but is slightly counterbalanced by the bigger sulfur affinity. Logically, the difference in affinities slightly decreases (for example $46 \mathrm{~kJ} \mathrm{~mol}^{-1}$ and $22.5 \mathrm{~kJ} \mathrm{~mol}^{-1}$ when considering $\mathrm{U}$ and $2 \mathrm{SU}$, respectively). Conversely, in the case of 4-thiouracil, the two effects are additive instead of being competitive, and the difference of affinities in favor of the $\mathrm{Y}$ site increases $\left(59 \mathrm{~kJ} \mathrm{~mol}^{-1}\right.$ when comparing $\mathrm{U}$ and $4 \mathrm{SU}$ ).

Structures and relative stabilities of $[\mathrm{Pb} \text { (thiouracil) }-\mathrm{H}]^{+}$ complexes. To be consistent with our previous study on uracil, we considered the different enolic and thioenolic forms of 2-thiouracil, 4-thiouracil and 2,4-dithiouracil.

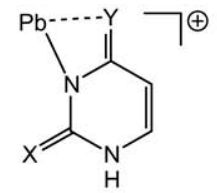

nSU-1<smiles></smiles>

nSU-4t<smiles></smiles>

nSU-7t<smiles>[X]c1nccc(=[V][Pb]C)[nH]1</smiles>

nSU-10t

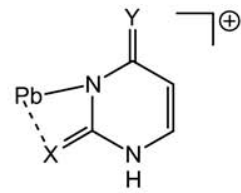

nSU-2

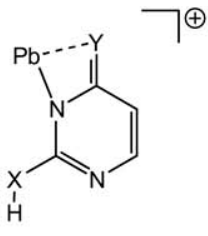

nSU-5t<smiles></smiles>

nSU-8t<smiles>[Y]C1=N[Pb]2P[Y]([H])N2C=C1</smiles>

nSU-11t

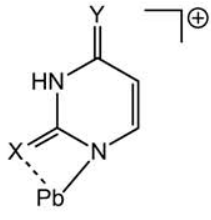

n-SU-3

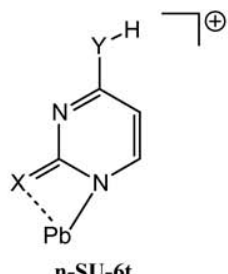

n-SU-6t

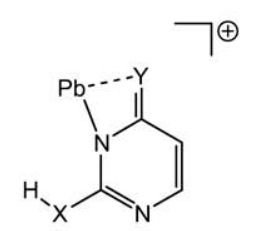

n-SU-9t<smiles></smiles>

n-SU-12<smiles></smiles>

dnSU-1<smiles>[X]C1=NC(=[X])NC=C1</smiles>

$\operatorname{dnSU}-2$
The various structures considered are presented in Scheme 2. The letter " $n$ " is used to identify the nucleobase, while the suffix " $\mathrm{t}$ " is added for tautomeric forms. We studied mono- and bi-coordination modes and we considered that deprotonation could occur on several sites: nitrogens, $C(5)$, and oxygens or sulfurs for tautomeric forms. We decided not to investigate in detail $\pi$-interactions because of the resulting distortion of the ring from planarity, which destroys the resonance delocalization and leads to high-energy species [33, 41]. Relevant bond lengths of the most stables structures obtained are given in Figure 3. Relative energies of the different structures are summarized in Table 3.

We found that B3LYP and G96LYP functionals give the same relative order of stability. Geometries are also similar, the bond lengths obtained with the G96LYP functional being slightly longer. For all the structures displayed in Scheme 2, the metal has an in-plane interaction with the nucleobase. As for doubly-charged complexes, $\mathrm{Pb}^{2+}$ ion has a marked preference for sulfur atoms. The most stable structures are bidentate and systematically involve interaction with one sulfur atom and either $\mathrm{N}(1)$ or $\mathrm{N}(3)$ deprotonated nitrogen atom. The stability order is again driven by the greater affinity of lead for sulfur and the zwitterionic effect. This can be illustrated for example by structures nSU-1 and nSU-2. 2SU-1 implies an interaction with the $\mathrm{C}(4)=\mathrm{O}$ group and is a minimum on the potential energy surface thanks to the zwitterionic effect. However, the energy difference with $2 \mathrm{SU}-2$ is rather important $(+49.3 \mathrm{~kJ}$ $\mathrm{mol}^{-1}$ ) due to very strong stabilization of $2 \mathrm{SU}-2$ provided by the $\mathrm{Pb} / \mathrm{S}$ interaction. For 4-thiouracil, $4 \mathrm{SU}-1$ structure is the global minimum, while $4 \mathrm{SU}-2$ is no longer a minimum but evolves towards 4 SU-1 during the optimization step. Interaction of lead with a thioenol group (nSU-11t) gives rise to local minima, which are very high in energy compared to the global minima $\left(+188.0 \mathrm{~kJ} \mathrm{~mol}^{-1}\right.$ for 2SU-11t). On the other hand, the metal remains on the oxygen when the sulfur atom is protonated (4SU/24SU-7t and 4SU/24SU-8t). Monodentate structures such as 2SU-10t may exist in the gas phase although they are highly energetic $(+226.8 \mathrm{~kJ}$ $\left.\mathrm{mol}^{-1}\right)$. However, this structure is not found for 4thiouracil and 2,4-dithiouracil, but evolves to a bidentate geometry by creating an interaction with the $C(5)$ atom, resulting in the only nonplanar forms.

2SU-12, 4SU-12, and 24SU-12 structures, which correspond to the formal deprotonation of C (5), are energetically accessible. Finally, structures corresponding to tautomeric forms appear sometimes particularly stable (e.g., 2SU-4t) but never correspond to the global minimum. This is in contrast with recent findings reported for other singly charged ions, such as protonated uracil $[42,43]$ and thiouracils [9] or [ $\mathrm{Cu}$ (thiouracils) $]^{+}[10]$ and $[\mathrm{Cu} \text { (thiouracils) }-\mathrm{H}]^{+}[12]$ complexes.

Natural population analysis. To give a picture of the charge distribution within the $[\mathrm{Pb} \text { (thiouracil) }-\mathrm{H}]^{+}$ species, we have carried out a natural population anal- 


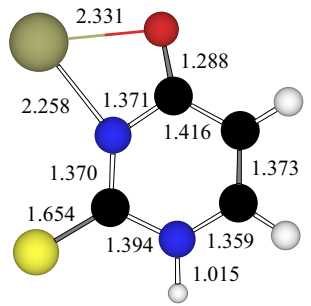

2SU-1

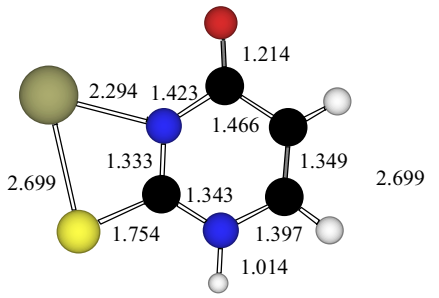

2SU-2

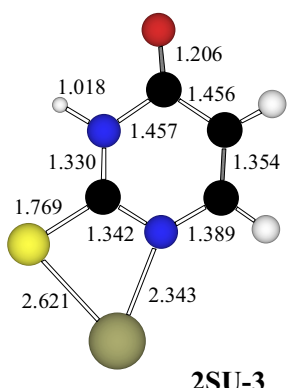

2SU-3

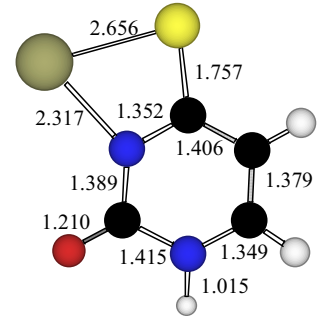

4SU-1

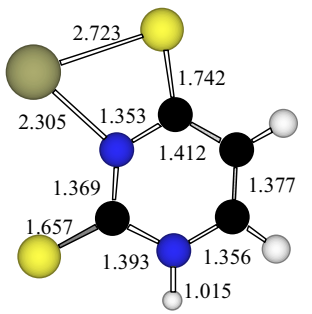

2,4SU-1

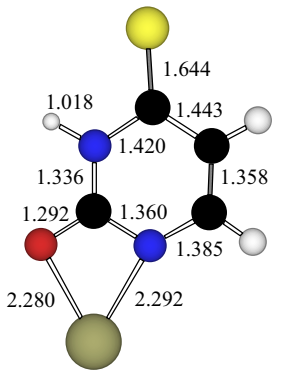

4SU-3

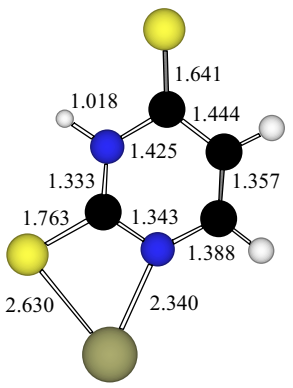

$2,4 \mathrm{SU}-3$

Figure 3. Geometry of the of most stable structures obtained for the $[\mathrm{Pb}(\mathrm{SU})-\mathrm{H}]^{+}$complexes with the B3LYP functional. Bond lengths are given in Angströms.

ysis (NPA) at the B3LYP/6-31G(d,p) level for all the structures investigated. Natural charges obtained for the metallic center are summarized in Table $3 S$ of the supplemental information. For the sake of comparison, values obtained for uracil are also included. From this table, one can see that an important charge transfer occurs from the ligand to the metal. This charge transfer is systematically more pronounced when the metal

Table 3. Relative energies $\left(\mathrm{kJ} \mathrm{mol}^{-1}\right)$ of the different structures considered

\begin{tabular}{|c|c|c|c|c|c|c|}
\hline \multirow[b]{2}{*}{ Structure } & \multicolumn{2}{|c|}{ 2-Thiouracil } & \multicolumn{2}{|c|}{ 4-Thiouracil } & \multicolumn{2}{|c|}{ 2-4-Dithiouracil } \\
\hline & $\Delta \mathrm{E}_{\mathrm{B} 3 \mathrm{LYP}}$ & $\Delta \mathrm{E}_{\mathrm{G} 96 \mathrm{LYP}}$ & $\Delta \mathrm{E}_{\mathrm{B} 3 \mathrm{LYP}}$ & $\Delta \mathrm{E}_{\mathrm{G} 96 \mathrm{LYP}}$ & $\Delta \mathrm{E}_{\mathrm{B} 3 \mathrm{LYP}}$ & $\Delta \mathrm{E}_{\mathrm{G} 96 \mathrm{LYP}}$ \\
\hline $\mathrm{nSU}-1$ & 49.3 & 32.4 & 0.0 & 0.0 & 0.0 & 0.0 \\
\hline nSU-2 & 0.0 & 0.0 & & & & \\
\hline nSU-3 & 12.4 & 9.1 & 82.8 & 78.1 & 32.5 & 29.4 \\
\hline $\mathrm{nSU}-4 \mathrm{t}$ & 1.9 & 2.1 & 74.5 & 71.4 & 11.7 & 10.1 \\
\hline$n S U-5 t$ & 63.9 & 61.6 & 26.3 & 30.6 & 23.4 & 25.2 \\
\hline $\mathrm{nSU}-6 \mathrm{t}$ & 20.6 & 19.9 & 79.2 & 76.0 & 16.1 & 14.4 \\
\hline $\mathrm{nSU}-7 \mathrm{t}$ & 24.2 & 23.0 & 90.8 & 90.0 & 27.0 & 27.8 \\
\hline $\mathrm{nSU}-8 \mathrm{t}$ & 40.2 & 39.8 & 100.6 & 98.7 & 36.7 & 36.5 \\
\hline $\mathrm{nSU}-9 \mathrm{t}$ & 78.3 & 74.9 & 67.5 & 69.1 & 38.4 & 39.0 \\
\hline $\mathrm{nSU}-10 \mathrm{t}$ & 226.8 & 199.7 & 147.7 & 142.3 & 152.8 & 29.4 \\
\hline $\mathrm{nSU}-11 \mathrm{t}$ & 188.0 & 171.1 & 226.8 & - & 201.6 & 10.1 \\
\hline nSU-12 & 106.2 & 99.9 & 74.1 & 70.7 & 79.6 & 25.2 \\
\hline
\end{tabular}


interacts with the sulfur atom, in agreement with previous results [44]. The charge transfer process is also more important compared with uracil (0.17-0.18 e-). This finding is consistent with the loss of $\mathrm{Pb}^{0}$ only observed with thiouracil derivatives. Examination of the natural bond orbitals (NBO) also shows that the $\mathrm{Pb}$ (II) lone pair is slightly polarized by a $6 \mathrm{p}$ contribution, ranging from $3.2 \%$ to $3.6 \%$. This feature is characteristic of hemi-directed structures [44]. The natural electronic configuration is typically of $6 \mathrm{~s}[1.94]$ $6 \mathrm{p}[0.72] \mathrm{sp}^{0.37}$ and of $6 \mathrm{~s}[1.94] 6 \mathrm{p}[0.51] \mathrm{sp}^{0.26}$ when $\mathrm{Pb}$ is coordinated to sulfur and oxygen, respectively. The electron transfer occurs essentially in the $6 \mathrm{p}$ orbitals of the metal. The value 0.37 for $\mathrm{Pb}(\mathrm{II}) \mathrm{sp}$ hybridization is greater than the one obtained for uracil [5], and confirms that the charge transfer is more important with sulfur. The charge transfer is also more pronounced than for $\mathrm{Pb}^{2+} /$ alkoxide systems [45]. On the other hand, the presence of two sulfur atoms (2,4-dithiouracil) does not particularly enhance the amount of charge transfer because lead association always involves a single sulfur atom. It is worth noting that the interaction between lead and sulfur is so strong that for most structures, it is accounted as a covalent bond with roughly $85 \%$ to $90 \%$ participation of the heteroatom lone pair and 15\% to $10 \%$ of $\mathrm{Pb} 6 \mathrm{p}$ orbital.

\section{Unimolecular Reactivity}

Formation of $[\mathrm{Pb}(\mathrm{NCX})]^{+}$and elimination of HNCX. Comparison of the bond lengths of cationized, neutral, and deprotonated species may bring useful insight about the chemical bonds that are likely to be activated during the collisional activation process. This can be correlated to the bond critical points (BCPs) deduced from the AIM theory. Generally, the bond length increases when the electron density at the $\mathrm{BCP}$ decreases. Note, however, that as already observed [5], the use of a pseudopotential to describe the metal results in unreliable BCPs for the $\mathrm{Pb}-\mathrm{X}$ bonds $(\mathrm{X}=\mathrm{N}$ or $\mathrm{O})$. AIM analysis obtained for 2-thio, 4-thio, and 2,4-dithiouracil are summarized in Tables 4S, 5S, and $6 \mathrm{~S}$ of the supplemental information, respectively. If we compare the deprotonated and cationized forms, we can see that the CS bond length increases systematically when $\mathrm{Pb}$ (II) interacts with sulfur atom $(+0.026 \AA$ for $2 \mathrm{SU}-2,+0.036 \AA$ for $4 \mathrm{SU}-1$, and $+0.036 \AA$ for $2,4 \mathrm{SU}-1$ with the B3LYP functional). Similarly, interaction with the N3 results in the important N3-C4 bond activation.

Loss of $\mathrm{HNCO} / \mathrm{HNCS}$ and formation of $[\mathrm{Pb}(\mathrm{NCO})]^{+} /$ $[\mathrm{Pb}(\mathrm{NCS})]^{+}$are among the fragment ions allowing to the unambiguous location of the sulfur atom. The $\mathrm{C}(2)$ (thio)carbonyl is specifically involved in these dissociation channels, and from labeling experiments performed with uracil [5], it is reasonable to assume that adjacent atoms should be also eliminated. Thus, by combining these experiments and the AIM analysis, we can propose different mechanisms accounting for these processes (see Figure 4 and Figure 5). Energy profiles have only been explored with the B3LYP functional since the use of the G96LYP functional has no effect on relative energies and, notably, the location of the transition states. Data obtained for 2,4-dithiouracil are provided as supplemental information (Figure $2 \mathrm{~S}$ ).

For 2-thiouracil (Figure 4), the loss the HNCS and the formation [PbCNS] ${ }^{+}$correspond to the $\mathrm{m} / \mathrm{z} 276$ and $\mathrm{m} / \mathrm{z}$ 266 ions, respectively. Starting from the global minimum (2SU-2), the formation of $[\mathrm{PbCNS}]^{+}$ion requires the activation of the $\mathrm{N}(3)-\mathrm{C}(4)$ bond, in agreement with the AIM analysis, followed by the ion dissociation. The associated energy barriers do not exceed $281 \mathrm{~kJ} \mathrm{~mol}^{-1}$. Two mechanisms associated with HNCS elimination may be proposed. The first one originates from $2 \mathrm{SU}-3$ through 2SU-TS6, with an activation barrier of $347.6 \mathrm{~kJ}$ $\mathrm{mol}^{-1}$. The second one involves $2 \mathrm{SU}-2$ as the starting point. The first step corresponds to a hydrogen shift between $C(5)$ and the carbonyl group, leading to the intermediate 2SU-A through 2SU-TS1. This activates the $\mathrm{C}(6)-\mathrm{N}(1)$ bond, which becomes easily cleavable, and 2SU-A evolves toward the intermediate 2SU-B through a TS (2SU-TS2) located around $299.3 \mathrm{~kJ} \mathrm{~mol}^{-1}$ above 2SU-2. Finally, 2SU-B may dissociate according to the elimination of HNCS. Note that in the forward direction, 2SU-TS3 directly collapses towards a structure in which the hydrogen attached to the carbonyl oxygen atom is now located onto the nitrogen atom. The same finding was also observed for 4-thio and 2,4-dithiouracil (Figure 5 and Figure 2S). Examination of Figure 4 indicates that these two pathways are of comparable energy, while the formation of $[\mathrm{PbNCS}]^{+}$is only slightly more favorable.

The MS/MS spectrum obtained with 4-thiouracil is characterized by the loss of HNCO and the formation of $\left[\mathrm{PbCNO}^{+}(\mathrm{m} / \mathrm{z} 292\right.$ and 250 ions, respectively). Examination of Figure 5 shows that these two processes, when originating in the global minimum $4 \mathrm{SU}-1$ are slightly more energetic than those involving the elimination of the sulfur atom (2-thiouracil), except for the elimination of HNCO from 4SU-3. However, 4SU-3 is less stable by $82.9 \mathrm{~kJ} \mathrm{~mol}^{-1}$ than the global minimum and therefore might be not generated. Finally, 2-thiouracil and 2,4-dithiouracil exhibit the same fragmentations, and comparison between Figure 4 and Figure $2 \mathrm{~S}$ indicates that energies associated with the various processes are globally similar. Finally, one may notice that these processes globally require more energy (ca. $100 \mathrm{~kJ} \mathrm{~mol}^{-1}$ ) than in the case of uracil [5].

\section{Elimination of $\mathrm{Pb}$ and $\mathrm{PbS}$}

Comparison with the data obtained for uracil shows that two particularly abundant ions are characteristic of thiouracils: (1) $\mathrm{m} / \mathrm{z} 127$ (Figure $2 \mathbf{b}$; elimination of the reduced metal $\mathrm{Pb}^{0}$ specifically observed with 4 -thiouracil, and (2) $\mathrm{m} / z 95$ corresponding to the loss of 240 mass units (PbS) and observed with 2-thiouracil (Figure 2a). These two dissociation channels are also detected for 2,4dithiouracil $(\mathrm{m} / \mathrm{z} 143$ and 111), the former being clearly 


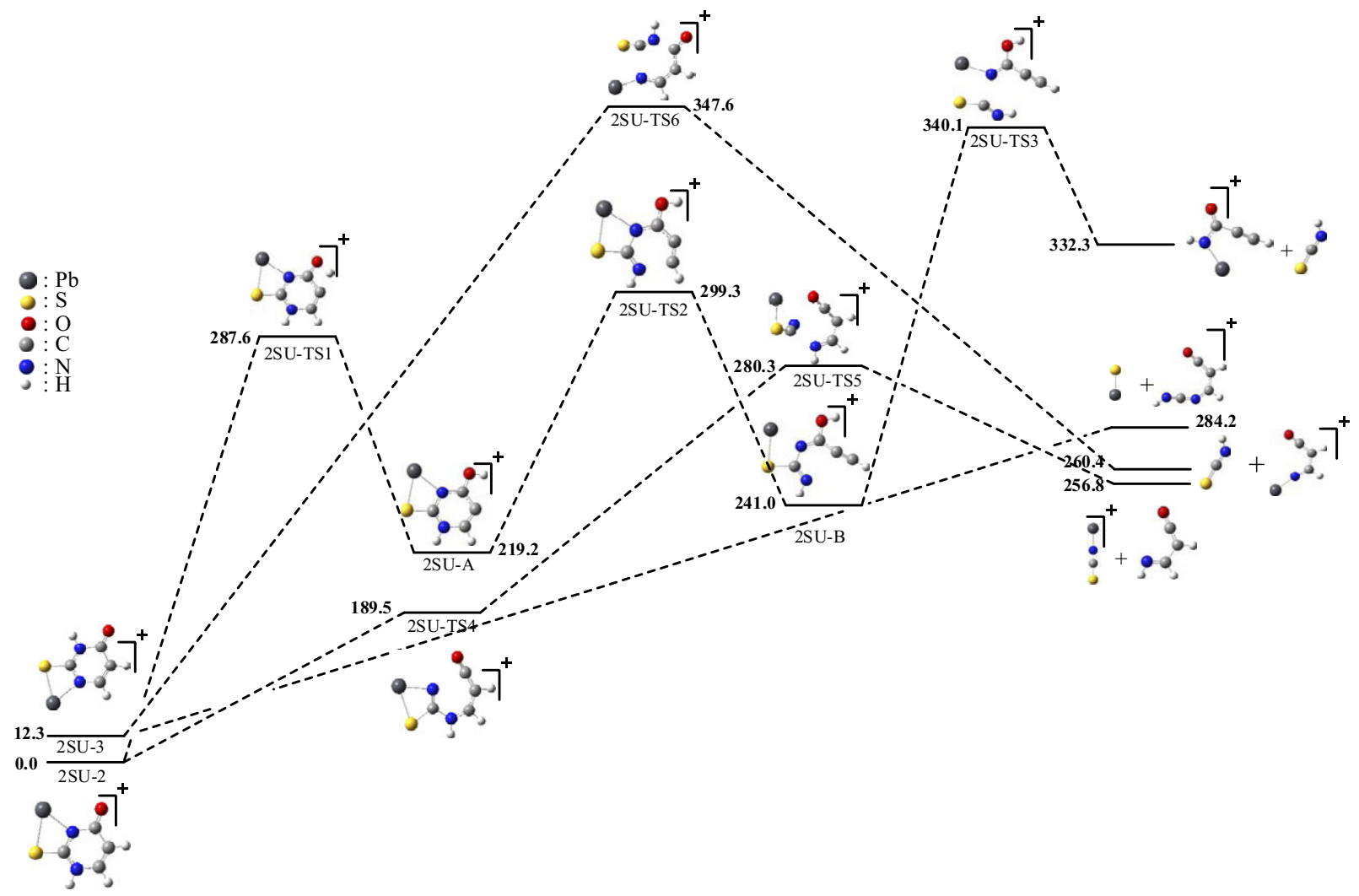

Figure 4. Potential energy surface corresponding to the loss of HNCS, PbS, and the formation of $[\mathrm{PbNCS}]^{+}$with origin in global minimum 2SU-2 and 2SU-3. Relative energies are in $\mathrm{kJ} \mathrm{mol}^{-1}$.

overwhelming. NBO examination of the most stable structures is consistent with a loss of PbS particularly favored when $\mathrm{Pb}$ interacts with $\mathrm{S}(2)$ of 2-thiouracil. As a matter of fact, two PbS bonds with a $p$ character are found for structure 2SU-2. This suggests that the PbS moiety would be preformed within $2 \mathrm{SU}-2$ and this is consistent with the intense $\mathrm{m} / \mathrm{z} 95$ observed on the MS/MS spectrum. On the other hand, only one bond is found between lead and sulfur atoms in the case of both 4SU-1 and 2,4SU-1.

To address this difference of behavior, the redox reaction energy of $\mathrm{Pb}^{2+}$ in presence of each thiouracil molecule has been also estimated. The data obtained are given below.

$$
\begin{aligned}
2 \mathrm{SU}+\mathrm{Pb}^{2+} & \longrightarrow & 2 \mathrm{SU}^{2+}(\mathrm{T})+\mathrm{Pb}^{0}(\mathrm{~T}) & \Delta \mathrm{E}=222.93 \mathrm{~kJ} / \mathrm{mol} \\
4 \mathrm{SU}+\mathrm{Pb}^{2+} & \longrightarrow & 4 \mathrm{SU}^{2+}(\mathrm{T})+\mathrm{Pb}^{0}(\mathrm{~T}) & \Delta \mathrm{E}=179.76 \mathrm{~kJ} / \mathrm{mol} \\
24 \mathrm{SU}+\mathrm{Pb}^{2+} & \longrightarrow & 24 \mathrm{SU}^{2+}(\mathrm{T})+\mathrm{Pb}^{0}(\mathrm{~T}) & \Delta \mathrm{E}=79.71 \mathrm{~kJ} / \mathrm{mol}
\end{aligned}
$$

These reactions may not take place during our experiments but the goal of these estimates is to get information about the ability of thiouracil derivatives to yield electrons to the metal. From these values, we can deduce that 2,4-dithiouracil and 4-thiouracil have a greater tendency to reduce the metal than 2-thiouracil.

The difference observed between $4 \mathrm{SU}$ and 2SU with respect to the $\mathrm{PbS}$ elimination fragment can also be deduced from the energy level of the exit channel associated with this fragmentation (see Figures 4 and 5). While for 2-thiouracil and 2,4-dithiouracil, loss of PbS is thermodynamically competitive with the other mechanisms, for 4-thiouracil the exit channel associated with $\mathrm{PbS}$ elimination lies higher in energy than the other dissociation routes.

In summary, these different estimates give useful insights about the different behavior of 2-thio and 4-thiouracil regarding the specific elimination of $\mathrm{Pb}^{0}$ and $\mathrm{PbS}$, even though the reason why these ions are much more intense than those corresponding to the pyrimidic ring cleavage remains unclear.

\section{Conclusions}

The experimental study of the gas-phase interactions between lead(II) ions and thiouracils mainly result in the formation of $[\mathrm{Pb} \text { (nucleobase) }-\mathrm{H}]^{+}$ions. These complexes have been extensively studied by MS/MS experiments. Fragmentation patterns observed with 2-thiouracil and 4-thiouracil are different, therefore establishing $\mathrm{Pb}^{2+}$ cationization as an efficient way to distinguish these isomers. Furthermore, some fragmentations were not observed with uracil, namely loss of $\mathrm{PbS}$ and elimination of reduced $\mathrm{Pb}^{\circ}$. It is also found that lead atom has a greater affinity for sulfur than for oxygen, and natural population analysis indicates that 


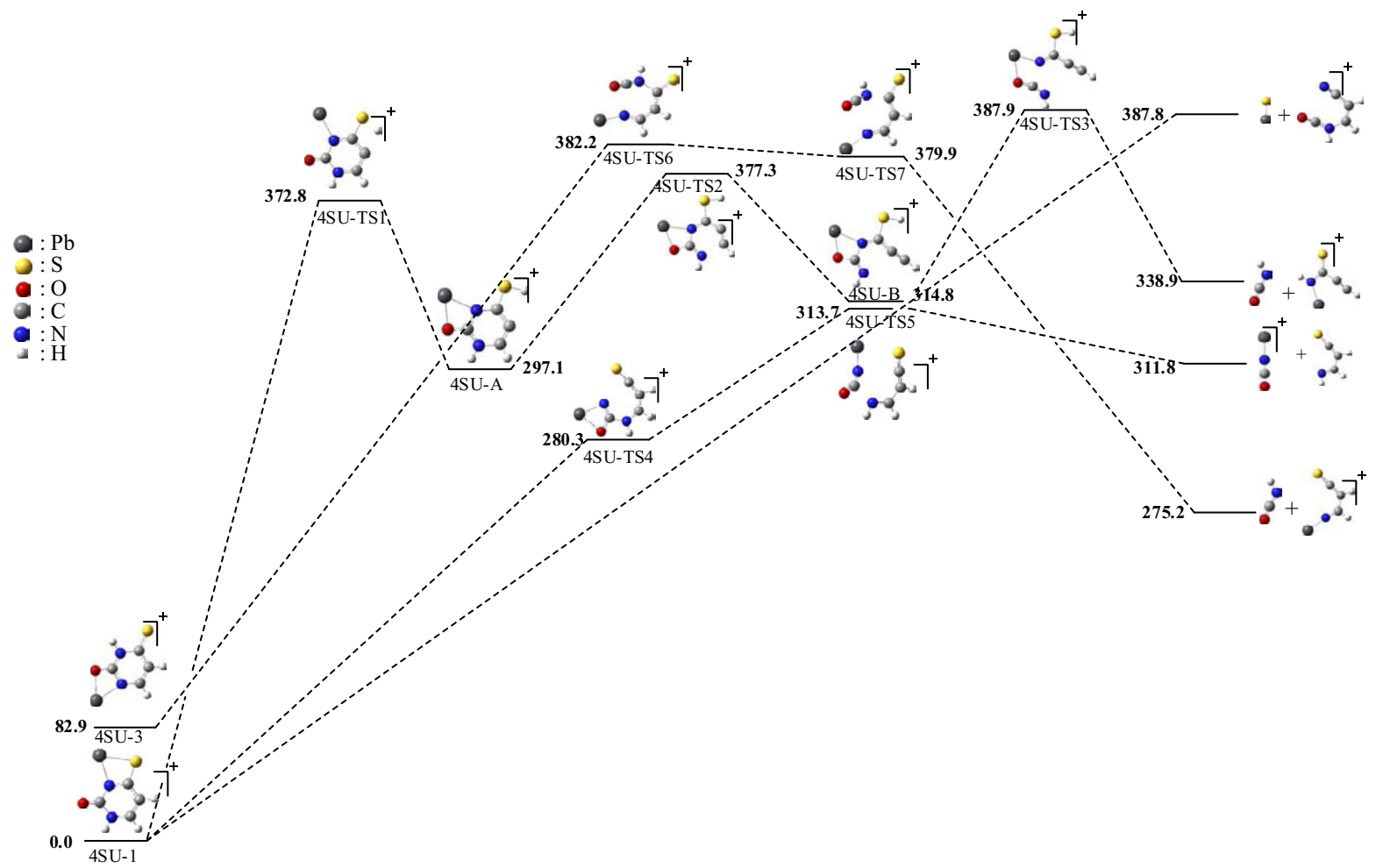

Figure 5. Potential energy surface corresponding to the loss of $\mathrm{HNCO}, \mathrm{PbS}$, and the formation of $[\mathrm{PbNCO}]^{+}$with origin in global minimum $4 \mathrm{SU}-1$ and $2 \mathrm{SU}-3$. Relative energies are in $\mathrm{kJ} \mathrm{mol}^{-1}$.

the charge transfer from the base moiety is more important with sulfur than with oxygen.

Comparison with the geometry of deprotonated nucleobases reveals that lead cationization induces significant geometrical modifications, and notably an important activation of the N3-C4 bond, which accounts for some of the observed fragmentations. Potential energy surface corresponding to the loss of HNCX and formation of $[\mathrm{PbNCX}]^{+}$are described, together with the energies of fragmentations required to expel either $\mathrm{PbS}$ or $\mathrm{Pb}^{\circ}$.

\section{Acknowledgments}

The authors acknowledge support for this work by the Ministerio de Educación y Ciencia of Spain, by DGI project no. BQU200600,894, and by project MADRISOLAR (ref. S-0505/PPQ/0225) of the Comunidad Autónoma de Madrid. The authors acknowledge a generous allocation of computational time at the CCC of the Universidad Autónoma de Madrid. They thank the Institut du Développement et des Ressources en Informatique Scientifique (IDRIS, CNRS) for computational time. They also thank Professor M. Yañez for fruitful discussion.

\section{Uncited References}

This section comprises of references that occur in the reference list but not in the body of the text. Please position each reference in the text or, alternatively, delete it. Any reference not dealt with will be retained in this section [31].

\section{References}

1. Farkas, W. R. Depolymerization of Ribonucleic Acid by Plumbous Ion Biochim. Biophys. Acta 1968, 155, 401-409.

2. Brown, R. S.; Hingerty, B. E.; Dewan, J. C.; Klug, A. Pb(II)-Catalyzed Cleavage of the Sugar-Phosphate Backbone of Yeast tRNA ${ }^{\text {Phe }}$ Implications for Lead Toxicity and Self-Splicing RNA. Nature 1983, 303, 543-546.

3. Brown, R. S.; Dewan, J. C.; Klug, A. Crystallographic and Biochemical Investigation of the Lead(II)-Catalyzed Hydrolysis of Yeast Phenylalanine tRNA. Biochemistry 1985, 24, 4785-4801.

4. Scott, W. G. RNA Structure, Metal Ions, and Catalysis. Curr. Opin. Chem. Biol. 1999, 3, 705-709.

5. Guillaumont, S.; Tortajada, J.; Salpin, J. Y.; Lamsabhi, A. M. Experimental and Computational Study of the Gas-Phase Interactions Between Lead(II) Ions and Two Pyrimidic Nucleobases: Uracil and Thymine. Int. J. Mass Spectrom. 2005, 243, 279-293.

6. Gutle, C.; Salpin, J. Y.; Cartailler, T.; Tortajada, J.; Gaigeot, M. P. Proton Transfers Induced by Lead(II) in a Uracil Nucleobase: A Study Based on Quantum Chemistry Calculations. J. Phys. Chem. A 2006, 110, 1168411694.

7. Lehninger, A. L. Biochemistry: The Molecular Basis of Cell Structure and Function 2nd eds.; Worth Publishers: New York, 1975.

8. Saenger, W. Advanced Texts in Chemistry, Principles of Nucleic Acid Structure,; Springer-Verlag: New York, 1984.

9. Lamsabhi, M.; Alcamí, M.; Mó, O.; Bouab, W.; Esseffar, M.; Abboud, J. L. M.; Yáñez, M. Are the Thiouracils Sulfur Bases in the Gas Phase? J. Phys. Chem. A 2000, 104, 5122-5130.

10. Lamsabhi, A. M.; Alcamí, M.; Mó, O.; Yáñez, M. Gas-Phase Reactivity of Uracil, 2-Thiouracil, 4-Thiouracil, and 2,4-Dithiouracil Towards the $\mathrm{Cu}^{+}$ Cation: A DFT Study. Chem. Phys. Chem. 2003, 4, 1011-1016.

11. Lamsabhi, A. M.; Alcamí, M.; Mó, O.; Yáñez, M.; Tortajada, J. Association of $\mathrm{Cu}^{2+}$ with Uracil and Its Thio Derivatives: A Theoretical Study. Chem. Phys. Chem. 2004, 5, 1871-1878.

12. Lamsabhi, A. M.; Alcamí, M.; Mó, O.; Yáñez, M.; Tortajada, J. Gas-Phase Deprotonation of Uracil- $\mathrm{Cu}^{2+}$ and Thiouracil- $\mathrm{Cu}^{2+}$ Complexes. J. Phys. Chem. A 2006, 110, 1943-1950.

13. Lamsabhi, A. M.; Alcamí, M.; Mó, O.; Yáñez, M.; Tortajada, J.; Salpin, J. Y. Unimolecular Reactivity of Uracil- $\mathrm{Cu}^{2+}$ Complexes in the Gas Phase. Chem. Phys. Chem. 2007, 8, 181-187.

14. Trujillo, C.; Lamsabhi, A. M.; Mó, O.; Yáñez, M.; Salpin, J. Y. Interaction of $\mathrm{Ca}^{2+}$ with Uracil and Its Thio Derivatives in the Gas Phase. Org. Biomol. Chem. 2008, 6, 3695-3702. 
15. Yang, Z. B.; Rodgers, M. T. Influence of Thioketo Substitution on the Properties of Uracil and Its Noncovalent Interactions with Alkali Metal Ions: Threshold Collision-Induced Dissociation and Theoretical Studies. J. Phys. Chem. A 2006, 110, 1455-1468.

16. Jayaweera, P.; Blades, A. T.; Ikonomou, M. G.; Kebarle, P. Production and Study in the Gas-Phase of Multiply Charged Solvated or Coordinated Metal-Ions. J. Am. Chem. Soc. 1990, 112, 2452-2454.

17. Chernushevich, I. V.; Loboda, A. V.; Thomson, B. A. An Introduction to Quadrupole-Time-of-Flight Mass Spectrometry. J. Mass Spectrom. 2001, 36, 849-865

18. Frisch, M. J.; Trucks G. W.; Schlegel H. B.; Scuseria G. E.; Robb M. A.; Cheeseman J. R.; Zakrzewski V. G.; J. A. Montgomery J.; Vreven T. Kudin K. N.; Burant J. C.; Millam J. M.; Iyengar S. S.; Tomasi J.; Barone V.; Mennucci B.; Cossi M.; Scalmi G.; Rega N.; Petersson G. A.; Nakatsuji H.; Hada M.; Ehara M.; Toyota K.; Fukuda R.; Hasegawa J.; Ishida M.; Nakajima T.; Honda Y.; Kitao O.; Adamo C.; Jaramillo J.; Gomperts R.; Stratmann R. E.; Yazyev O.; Austin I.; Cammi R.; Pomelli C.; Ochterski J.; Ayala P. Y.; Morokuma K.; Voth G. A.; Salvador P.; Dannenberg J. J.; Zakrzewski V. G.; Dapprich S.; Daniels A. D.; Strain M. C.; Farkas O.; Malick D. K.; Rabuck A. D.; Raghavachari K.; Foresman J. B.; Ortiz J. V.; Cui Q.; Baboul A. G.; Clifford S.; Cioslowski J.: Stefanov B. B.; Liu G.; Liashenko A.; Piskorz P.; Komaromi I.; Martin R. L.; Fox D. J.; Keith T.; Al-Laham M. A.; Peng C. Y.; Nanayakkara A.; Challacombe M.; Gill P. M. W.; Johnson B.; Chen W.; Wong M. W.; Gonzalez C.; Pople J. A. Gaussian03, Rev. C.02; Gaussian, Inc.: Wallingford, CT 2003.

19. Lee, C.; Yang, W.; Parr, R. G. Development of the Colle-Salvetti Correlation-Energy Formula into a Functional of the Electron Density. Phys. Rev. B 1988, 37, 785-789.

20. Becke, A. D. Density-Functional Thermochemistry. 3. The Role of Exact Exchange. J. Chem. Phys. 1993, 98, 5648-5652.

21. Gill, P. M. W. A New Gradient-Corrected Exchange Functional. Mol. Phys. 1996, 89, 433-445.

22. Küchle, W.; Dolg, M.; Stoll, H.; Preuss, H. Ab Initio Pseudopotentials for $\mathrm{Hg}$ Through Rn. I. Parameter Sets and Atomic Calculations. Mol. Phys. 1991, 6, 1945-1963.

23. Salpin, J. Y.; Tortajada, J.; Alcamí, M.; Mó, O., Yáñez, M. Optimization of Extended Basis Sets and Assessment of Different Theoretical Schemes for Pb Containing Compounds. Chem. Phys. Lett. 2004, 383, 561-565.

24. Hoyau, S.; Ohanessian, G. Complexation of Small Organic Molecules by $\mathrm{Cu}^{+}$. Chem. Phys. Lett. 1997, 280, 266-272.

25. Kemper, P. R.; Weis, P.; Bowers, M. T.; Maitre, P. Origin of Bonding Interactions in $\mathrm{Cu}^{+}(\mathrm{H}-2)$ (n) Clusters: An Experimental and Theoretical Investigation. J. Am. Chem. Soc. 1998, 120, 13494-13502.

26. Alcamí, M.; Luna, A.; Mó, O.; Yáñez, M.; Boutreau, L.; Tortajada, J. Experimental and Theoretical Investigation of the Reactions Between Glucose and $\mathrm{Cu}^{+}$in the Gas Phase. J. Phys. Chem. A 2002, 106, 2641-2651.

27. González, L.; Mó, O., Yáñez, M. High-Level Ab Initio Versus DFT Calculations on $\left(\mathrm{H}_{2} \mathrm{O}_{2}\right)(2)$ and $\mathrm{H}_{2} \mathrm{O}_{2}-\mathrm{H}_{2} \mathrm{O}$ Complexes as Prototypes of Multiple Hydrogen Bond Systems. J. Comput. Chem. 1997, 18, 1124-1135.

28. González, L.; Mó, O.; Yáñez, M. High-Level Ab Initio Calculations on the Intramolecular Hydrogen Bond in Thiomalonaldehyde. J. Phys. Chem. A 1997, 101, 9710-9719.
29. González, L.; Mó, O.; Yáñez, M. High Level Ab Initio and Density Functional Theory Studies on Methanol-Water Dimers and Cyclic Methanol(Water)(2) Trimer. J. Chem. Phys. 1998, 109, 139-150.

30. Glendening, E. D.; Reed, A. E.; Weinhold, F. NBO version 3.1.

31. In International Series of Monographs on Chemistry; 22, Atoms in Molecules: A Quantum Theory. Bader, R. F. W., Ed.; Clarendon Press/Oxford University Press: Oxford, New York, 1990.

32. Matta, C. F.; Boyd, R. H. The Quantum Theory of Atoms in Molecules; Wiley-VCH: Weinheim, 2007.

33. Rodgers, M. T.; Armentrout, P. B. Noncovalent Interactions of Nucleic Acid Bases (Uracil, Thymine, and Adenine) with Alkali Metal Ions. Threshold Collision-Induced Dissociation and Theoretical Studies. J. Am. Chem. Soc. 2000, 122, 8548-8558.

34. Katritzky, A. R.; Baykut, G.; Rachwal, S.; Szafran, M.; Caster, K. C. Eyler, J. The Tautomeric Equilibria of Thio Analogs of Nucleic-Acid Bases. 1. 2-Thiouracil-Background, Preparation of Model Compounds, and Gas-Phase Proton Affinities. I. Chem. Soc. Perkin Trans. 2 1989, 1499-1506.

35. Katritzky, A. R.; Szafran, M.; Stevens, J. The Tautomeric Equilibria of Thio Analogs of Nucleic-Acid Bases. 2. AM1 and Ab Initio Calculations of 2-Thiouracil and Its Methyl-Derivatives. J. Chem. Soc. Perkin Trans. 2 1989, 1507-1511.

36. Katritzky, A. R.; Szafran, M.; Pfister-Guillouzo, G. The Tautomeric Equilibria of Thio Analogs of Nucleic-Acid Bases. 3. Ultraviolet Photoelectron-Spectra of 2-Thiouracil and Its Methyl-Derivatives. J. Chem. Soc. Perkin Trans. 2 1990, 871-876.

37. Leszczynski, J.; Lammertsma, K. 2,4-Dithiouracil Tautomers: Structures and Energies. J. Phys. Chem. 1991, 95, 3128-3132.

38. Leszczynski, J.; Sponer, J. 2,4-Diselenouracil Tautomers: Structures, Energies, and a Comparison with Uracil and 2,4-Dithiouracil. J. Mol Struct. Theochem. 1996, 388, 237-243.

39. Vaquero, V.; Sanz, M. E.; Lopez, J. C.; Alonso, J. L. The Structure of Uracil: A Laser Ablation Rotational Study. J. Phys. Chem. A 2007, 111, 3443-3445.

40. Kurinovich, M. A.; Phillips, L. M.; Sharma, S.; Lee, J. K. The Gas Phase Proton Affinity of Uracil: Measuring Multiple Basic Sites and Implications for the Enzyme Mechanism of Orotidine 5'-Monophosphate Decarboxylase. Chem. Commun. 2002, 2354-2355.

41. Zhu, W. L.; Luo, X. M.; Puah, C. M.; Tan, X. J.; Shen, J. H.; Gu, J. D.; Chen, K. X.; Jiang, H. L. The Multiplicity, Strength, and Nature of the Interaction of Nucleobases with Alkaline and Alkaline Earth Meta Cations: A Density Functional Theory Investigation. J. Phys. Chem. A 2004, 108, 4008-4018.

42. Wolken, J. K.; Turecek, F. Proton affinity of uracil. A Computational Study of Protonation Sites. J. Am. Soc. Mass Spectrom. 2000, 11, 1065 1071.

43. Salpin, J. Y.; Guillaumont, S.; Tortajada, J.; MacAleese, L.; Lemaire, J.; Maitre, P. Infrared Spectra of Protonated Uracil, Thymine, and Cytosine. Chem. Phys. Chem. 2007, 8, 2235-2244

44. Shimoni-Livny, L.; Glusker, J. P.; Bock, W. Lone Pair Functionality in Divalent Lead compounds. Inorg. Chem. 1998, 37, 1853-1867.

45. Salpin, J. Y.: Tortajada, J. Gas-Phase Reactivity of Lead(II) Ions with D-Glucose. Combined Electrospray Ionization Mass Spectrometry and Theoretical Study. J. Phys. Chem. A 2003, 107, 2943-2953. 